\title{
O ELEMENTO FINANCEIRO E A EDUCAÇÃO PARA O CONSUMO RESPONSÁVEL
}

Abdala Mohamed Saleh*

Pascoalina Bailon de Oliveira Saleh**

RESUMO: Neste artigo, discute-se o aspecto financeiro, no âmbito da Educação para o Consumo Responsável. Descreve-se, didaticamente, o cenário financeiro atual, no qual se sobressai a crise financeira mundial. A crise influencia o movimento de estímulo e contenção das economias mundiais e tem reflexos nos padrões de consumo, podendo, em situações de oferta indiscriminada de crédito, favorecer o superendividamento das famílias. Nesse contexto, em 2010, surge, no Brasil, a Estratégia Nacional de Educação Financeira - ENEF, um programa de Estado que visa a educar financeiramente a população. Discute-se, brevemente, esse programa e assume-se a posição de que a educação financeira deve ser inserida no âmbito do consumo responsável, o qual engloba as vertentes meio ambiente, saúde, publicidade, direito e ética. Analisam-se quatro exemplos de fatos/situações noticiados pela mídia, a fim de evidenciar a complexidade envolvida no consumo. Finalmente, situa-se a relação entre a educação para o consumo e o sentido de educação freiriano.

Palavras-chave: Educação Financeira; Consumo Responsável; Ensino.

* Doutor em Física pelo Instituto de Física Gleb Wataghin da Universidade Estadual de Campinas (UNICAMP); Professor Associado do Departamento de Matemática e Estatística da Universidade Estadual de Ponta Grossa (UEPG/PR). E-mail: abdala.saleh@gmail.com

* * Doutora em Lingüística pela Universidade Estadual de Campinas (UNICAMP); Professora Associada do Departamento de Letras da Universidade Estadual de Ponta Grossa (UEPG/PR). E-mail: pbosaleh@gmail.com 
THE FINANCIAL ELEMENT AND THE EDUCATION FOR RESPONSIBLE CONSUMPTION

ABSTRACT: This article discusses the financial aspect in the scope of Education for Responsible Consumption. It presents a didactic description of the current financial scenario, in which the global financial crisis stands out. Such crisis influences the motion stimulus and restraint of world economies and it is reflected in consumption patterns, which may, in situations of indiscriminate supply of credit, favor the indebtedness of households. In this context, it was created in Brazil in 2010 the National Strategy for Financial Education - ENEF, a State program that aims to educate people financially. This program is briefly discussed and it is assumed that financial education must be inserted under the responsible consumption, which includes aspects regarding environment, health, advertising, law and ethics. It analyzes four examples of facts/situations reported by the media to highlight the complexity involved in consumption. Finally, this paper establishes a relationship between consumer education and the Freirian concept of education.

Keywords: Financial Education, Responsible Consumption, Teaching.

\section{Introdução}

Ainda estamos vivendo os desdobramentos da crise financeira mundial que eclodiu em 2008 e que trouxe para dentro dos lares brasileiros constantes referências ao tema, ora nos exaltando ao consumo, ora fazendo análise da situação brasileira e das providências aqui tomadas, ora se referindo aos países mais atingidos do momento etc.

A situação mundial e local, aliada às constantes evoluções tecnológicas e ao sistema de crédito, tem favorecido o aumento do consumo, que, aliado à ausência de uma educação financeira, tem favorecido o endividamento. Nesse contexto, o governo, juntamente com a iniciativa privada, lançou o Programa ENEF - Estratégia Nacional de Educação Financeira (BRASIL, 2010; O QUE É, 2012; INSTITUIÇÕES, 2012; LEGISLAÇÃO, 2012).

Diante disso, o propósito deste trabalho é partir da situação brevemente exposta acima e aprofundá-la, a fim de refletir sobre a educação financeira, procurando situá-la no âmbito da Educação para o Consumo Responsável (IDEC; INMETRO, 2002a; 2002b; 2002c e 2002d; SALEH, 2010; SALEH; SALEH, 2010; SALEH; SALEH, 2012), proposta que pretende contribuir para a abordagem do tema prioritariamente no ensino básico, no contexto dos temas transversais previstos pelos PCNs (BRASIL, 1998). 
Uma forma de definir a escola é tomá-la, como o faz Colello (2003), como "um território de especialistas em 'ensinar o mundo longe do mundo"". Trata-se, de acordo com a autora, de "um espaço privilegiado de uma aprendizagem sistematizada que requer certo afastamento do real em benefício de uma re-organização burocrática, temporal e metodológica supostamente favorável à aprendizagem" (COLELLO, 2003, p.2).

Pensar a questão financeira no âmbito do ensino formal só é possível em função desse afastamento do real de que fala a autora. Paradoxalmente, é esse mesmo afastamento que, esperamos, nos permitirá situar o elemento financeiro em um contexto mais amplo, de forma a fornecer subsídios para a abordagem do tema na escola, aproximando-o do real em sua complexidade, condição para que se garanta à educação o sentido de prática crítica e transformadora, que propicie o desenvolvimento da autonomia dos educandos, conforme insiste Paulo Freire (2011).

\section{0 aspecto financeiro, 0 ENEF e a educação para o consumo responsável}

Atualmente, a temática financeira tem tido papel de destaque nos meios de comunicação de massa de nosso país e do mundo, devido à crise mundial no setor. De modo simplificado, podemos dizer que isso se deve a um só fenômeno, a grave crise financeira global, que se manifestou de forma mais aguda em dois momentos, 2008 e 2011. As causas dessa crise podem ser explicadas como a soma de dois termos: 1) a criação de riqueza fictícia iniciada nos anos 80; e 2) mercados autorregulados e eficientes (BRESSER-PEREIRA, 2010).

A primeira é tipicamente lembrada como "bolhas", que representam uma valorização "virtual" dos preços que pode ocorrer em empresas, produtos ou serviços. No caso, há uma grande discrepância entre o preço razoavelmente esperado e o efetivamente praticado, sendo que, em algum momento, obrigatoriamente, acontecerá uma correção, levando à crise, como a que o mundo está vivenciando. Nesse sentido, surgem também indagações sobre em que medida se pode controlar a correlação anormal de forças existentes entre o "sistema financeiro e a economia real" (DOMINGOS, 2008). Boa parte das pessoas desconhece que nós, consumidores, estamos sofrendo os efeitos de ambas as forças. Esse fato 
deve-se, provavelmente, à nossa percepção incompleta de que tudo gira em torno apenas da economia do dia a dia (supermercado, farmácia, aluguel etc.), pois é essa que está concretamente posta aos nossos olhos. Surgem aí condições propícias para a existência de desvios nas relações de consumo, nas quais o consumidor tende a se fragilizar ainda mais. Um exemplo dessa fragilidade manifesta-se na forma de superendividamento (RIO GRANDE DO SUL, 2011), à qual voltaremos mais adiante.

A segunda causa, não dissociada da primeira, está relacionada a um enfraquecimento da atuação do Estado no sentido de coibir abusos, como verificamos no caso das agências reguladoras existentes no Brasil, que, muitas vezes, não protegem adequadamente o interesse público. Podemos citar o caso dos bancos, que não têm concorrência entre si. Em contrapartida, houve avanço no setor de supermercados, que beneficia os consumidores pelo aumento de opções disponíveis. Outro exemplo em que houve avanço foi o caso da implantação da portabilidade na telefonia fixa e móvel (MANIR, 2008). Vale ressaltar que, cada vez mais, é esperado que a regulação de mercados nacionais e internacionais ocorra de forma associada, pois a economia mundial está ininterruptamente ligada em rede. Os preços observados no Brasil e no mundo são reflexos disso (LEITÃO, 2011).

A partir de 2008, assistimos a uma enorme turbulência em todo o mundo, manifestada na forma de abalo de instituições financeiras tidas como sólidas, quedas súbitas nos preços das ações em bolsa de valores, forte desaceleração das economias em países desenvolvidos, preços das commodities' abaixo do normal, quedas nos índices de confiança e proliferação da desaceleração. Desapareceu a ideia de que a crise, iniciada nos EUA (maior potência industrial do mundo), está descasada com a do resto do mundo (FRIAS, 2008). A crise norte-americana, do subprime ${ }^{2}$, segue o mesmo princípio dos dois termos já tratados no início do texto, ou seja, a existência de preços fictícios dos ativos devido à falta de regulação do mercado financeiro. Esse estado de coisas obrigou que os governos, à custa do aumento de suas dívidas públicas, ${ }^{3}$ lançassem pacotes de ajuda para impulsionar a economia, o emprego, reduzir déficits fiscais (gastos do governo acima da arrecadação) e evitar "bolhas" de ativos (O ESTADO DE SÃO PAULO, 2009).

No decorrer do tempo, tem-se confirmado que a crise não tem solução fácil, pois, além do que foi dito, os governantes estatizaram rom- 
bos, gerando dívida pública, que eles próprios permitiram, pagando juros altos a quem lhes emprestasse dinheiro via títulos públicos; mantiveram taxas de juros baixas e longas ao consumidor, facilitando a concessão de crédito para quem não tinha condições de pagar.

Os países da região do Euro apresentam condições econômicas bastante frágeis (Grécia, Portugal, Irlanda e Espanha). Outro fato histórico foi que, recentemente, pela primeira vez na história, a agência de risco Standard \& Poors rebaixou a nota de crédito dos EUA (HALFELD, 2011). A dívida pública americana atingiu o valor do PIB $^{4}$ do país (US\$ 14,3 trilhões), o máximo autorizado pelo Congresso (ARBEX JÚNIOR, 2011). Há uma grande preocupação sobre até quando a China "puxará" o crescimento mundial (GODOY; MEDINA; GAZZEL JÚNIOR, 2006), país, aliás, muito importante na economia brasileira e mundial do ponto de vista comercial.

No Brasil, a crise deflagrada em 2008 impactou a economia de maneira distinta da observada em países ricos, visto que o consumo do mercado interno se manteve vigoroso. Para isso, o governo lançou uma ofensiva publicitária, tendo o próprio presidente Lula como protagonista, incentivando a população a não ter medo de comprar a "casinha, o carro...” (MANIR, 2008). O governo também teve forte participação reduzindo impostos sobre produtos industrializados (IPI) de eletrodomésticos da linha branca (fogão, geladeira, máquina de lavar e tanquinho), o que, além de facilitar o acesso a esses bens de consumo duráveis para a população de mais baixa renda, favoreceu a ampliação do emprego e a manutenção do crescimento do varejo e da indústria. Além disso, o governo lançou medidas tributárias de cunho ambiental, estendendo ainda mais o prazo de redução de IPI aos eletrodomésticos que consomem menos energia. Aqui fazemos um parêntese para lembrar que é notório que a questão ambiental ainda não é suficientemente levada em conta na tomada de decisão dos consumidores. Em outras palavras, o preço, no momento da compra, vem antes do gasto de energia produzido pelo produto (GALVÃO, 2009), ainda que, ao longo da vida útil do eletrodoméstico, a economia de energia compense, também, do ponto de vista financeiro. Como veremos, a questão ambiental, relativamente ao aspecto financeiro, poderá ser considerada de forma mais ampla através do termo Preço1(MA) da equação Preçoecr e, também, dos quatro exemplos que serão analisados na parte final do texto. 
Outro estímulo do governo à economia foi a ampliação do Bolsa Família, programa de transferência de renda do governo federal, que também produziu um efeito de aquecimento econômico multiplicador em economias locais do país, possibilitando à população mais pobre o acesso a bens duráveis (BASTOS, 2008). Para esse público, o meio para adquirir tais bens tem sido o microcrédito concedido, por exemplo, pelo Banco do Brasil. Poderíamos citar outras tantas formas de se aquecer a economia brasileira, no período de crise financeira: elevação constante do salário mínimo, estabilidade financeira, aumento do número de trabalhadores com carteira assinada, ampliação do crédito consignado (desconto em folha de pagamento) etc. (BASTOS, 2008), porém, acreditamos serem essas suficientes para o espaço e propósito deste artigo.

No cenário do primeiro tempo da crise, em 2008, vimos, em escala global, uma queda abrupta do crédito, via maior seletividade para concessão e custo maior. Essa ação produziu severas contrações das economias do mundo. Em nosso país, como já dissemos, através de bancos públicos, cobrando taxas de seus serviços menores que a de bancos privados, o governo brasileiro incentivou a economia também facilitando o acesso ao crédito (LOYOLA, 2009). Posteriormente, isso se refletiu claramente através do aumento do PIB (RODRIGUES, 2010). Comumente, nessa situação, há uma elevação da procura por produtos e serviços, e os seus preços tendem a aumentar, gerando inflação. A solução adotada pela política monetária do Brasil tem sido a de elevar a taxa de juros (remuneração pelo capital emprestado), atraindo mais compradores de seus títulos do governo, diminuindo o consumo e a circulação de dinheiro, o que desacelera o crecimento do país. Assim, de maneira geral, o dueto inflação-juros opera no mesmo sentido: o aumento (diminuição) da inflação obriga a um aumento (diminuição) da taxa de juros (GODOY; MEDINA; GAZZEL JÚNIOR, 2006).

Já nos referimos à interdependência entre o estímulo da economia e o crédito, sendo que este permite que uma dada compra a um dado preço, em um dado lugar e em um dado tempo, possa ser paga em um tempo futuro (ou em parcelas futuras). A questão temporal torna-se fundamental na concessão do crédito, pois, quanto maior o tempo concedido ao consumidor, maior será também o preço pago por ele. Essa quantidade, a mais, é a taxa de juros, que representa remuneração pelo capital emprestado ao consumidor (TOSI, 2003). Aqui, destacamos o cartão de 
crédito como um elemento simbólico, visto que, por meio dele, as compras podem ser realizadas em parcelas, mediante um acréscimo do seu preço. É importante salientar ainda que o público de baixa renda possui 69\% dos cartões de crédito existentes no Brasil, configurando um novo perfil de consumidor no Brasil (CLASSE C, 2009). O cálculo do referido acréscimo (taxa de juros), em função do tempo, é um grande desafio à compreensão da maioria dos consumidores e contribui para um maior descontrole ou superendividamento (RIO GRANDE DO SUL, 2011) nas compras a crédito, pois, como podemos observar, " $12 \%$ da população deve 5 vezes a sua renda" (JÚNIOR, 2010). Ainda assim, o nível geral de endividamento do brasileiro é considerado baixo pelos economistas, mas a tendência é que as dívidas cresçam em função da expansão econômica e do aumento de renda.

Existe uma correlação entre valor elevado de taxa de juros cobrada do consumidor e o seu nível elevado de endividamento. Atualmente, dentre as famílias brasileiras endividadas, $72 \%$ o estão com o cartão de crédito, sendo que este possui uma taxa de juros de 238,30\% (PESQUISA CNC, 2012; PESQUISA, 2012). Ambas as porcentagens representam os maiores valores dentre as opções de crédito.

O governo promoveu uma redução de taxa de juros de 12,42\% em 21/07/2011 até 7,25\% em 17/04/2013, de forma a manter o crescimento do consumo e favorecer a competitividade das empresas nacionais no cenário mundial (D’AGOSTO, 2013). Essa redução foi plenamente aceitável, uma vez que os lucros dos bancos, ${ }^{5}$ incluindo-se os públicos federais, estavam elevadíssimos antes desse período. Além de potencialmente favorecer a diminuição do nível de endividamento dos consumidores, tratou-se de uma importante justificativa para a necessidade de uma Educação Financeira eficiente. Dadas as circunstâncias políticas e econômicas, o valor da taxa de juros foi elevado novamente a 9,00\% em 05/09/2013 (HISTÓRICO, 2013), ficando, porém, nesse momento, ainda muito abaixo dos 12,42\% de maio de 2011.

$\mathrm{O}$ ato de consumir relaciona-se intimamente ao fator subjetivo de sentimento de felicidade, de bem-estar coletivo em adquirir produtos, antes acessíveis apenas às classes sociais mais elevadas (GIANNETTI, 2002). Simultaneamente, o mesmo sentimento aplaca a preocupação desses consumidores com futuras dívidas. Estudos indicam que a delimitação do grau de satisfação de um país é de PIB per capita de, no máximo, US\$ 
10 mil anuais (aproximadamente $\mathrm{R} \$ 23.000,00 \mathrm{em}$ setembro de 2013). Isto é, o crescimento traz felicidade aos países extremamente pobres até o valor acima referido. A partir desse valor, não há alteração relevante do número dos que se consideram felizes ou infelizes. Esse foi o caso do crescimento visto em regiões desenvolvidas, como EUA, Europa e Japão, na segunda metade do século XX (GIANNETTI, 2002). O IBGE indicou que, em 2012, o PIB per capita foi de R $\$ 22.402,00^{6}$ (PORTO, 2013), significando que o Brasil está próximo de atingir o valor limite, o que o equipararia, nesse aspecto, a nações ricas (SEGALLA; VILLAMÉA, 2010). Podemos considerar o PIB per capita como um parâmetro interessante, mas devemos vê-lo com cuidado, pois uma boa renda per capita não assegura que os índices de concentração de renda e de desigualdade social sejam baixos.

Como expusemos anteriormente, o desenvolvimento da economia atual está, paradoxalmente, condicionado ao grau de endividamento da nossa população (JÚNIOR, 2010; RODRIGUES, 2010), pois, ainda que a política de redução dos juros seja retomada, é pouco provável que haja uma queda abrupta, porque isso levaria a outras consequências graves, como a alta da inflação. Nesse cenário de aumento de renda das classes menos abastadas e de maior acesso ao crédito, devemos levar em conta também as mudanças em curso em direção ao consumo mediado pelas novas tecnologias, em especial, pela internet. Esta permite o acesso a informações e a todo tipo de transferência de dados em escala mundial. Segundo o site do DCI, estima-se que, em apenas dois anos, do primeiro semestre de 2009 ao mesmo período de 2011, os "e-consumidores" aumentaram em cerca de 2 milhões, dos quais " $61 \%$ vieram de famílias com renda mensal de até $\mathrm{R} \$ 3$ mil, sendo em maioria (55\%) mulheres" (BAIXA, 2011).

A oferta indiscriminada de crédito e a falta de educação necessária para analisar os riscos envolvidos no ato de consumir podem levar a casos de superendividamento (RIO GRANDE DO SUL, 2011), gerando custos a órgãos de defesa do consumidor e, curiosamente, a organismos do próprio Estado (Defensoria Pública) (DPSP, 2010). Observa-se, assim, um circuito fechado, no qual o governo (nós, contribuintes) é, ao mesmo tempo, o principal agente, que impulsiona e corrige o consumo não responsável. Esse paradoxo é reiterado quando se vê que o governo lança, como veremos a seguir, a Estratégia Nacional de Educação Financeira - 
ENEF (BRASIL, 2010; O QUE É, 2012; LEGISLAÇÃO, 2012), tendo como parceiros realizadores instituições financeiras (INSTITUIÇÕES, 2012) que cobram exageradamente pelo crédito ao consumidor.

Nesse cenário, que se define pelas mudanças econômicas, sociais e tecnológicas dos últimos anos, as quais vêm viabilizando o acesso ao consumo, mas também favorecendo o endividamento, surge, através do Decreto $\mathrm{n}^{\circ}$ 7.397, de 22 de dezembro de 2010, a denominada Estratégia Nacional de Educação Financeira - ENEF (BRASIL, 2010). Trata-se de um programa de Estado que foi iniciado pelas entidades e órgãos integrantes do Comitê de Regulação e Fiscalização dos Mercados Financeiros, de Capitais, de Seguros, de Previdência e Capitalização - COREMEC, que são autarquias ${ }^{7}$ ligadas aos Ministérios da Fazenda e da Previdência. A iniciativa insere-se numa tendência mundial, seguindo recomendação da OCDE - Organização para a Cooperação e Desenvolvimento Econômico (SAVOIA; SAITO; SANTANA, 2007), e tem o intuito de implementar um conjunto de ações que visem a educar financeiramente a população. Os parceiros realizadores governamentais são os Ministérios da Educação e da Justiça, e os não governamentais são, entre outros, ${ }^{8}$ a FEBRABAN (Federação Brasileira de Bancos), o Instituto Unibanco, BM\&FBOVESPA ${ }^{9}$ etc. (INSTITUIÇÕES, 2012).

Dessa forma, os objetivos do ENEF são:

- Promover e fomentar a cultura de Educação Financeira no país;

- Ampliar o nível de compreensão do cidadão para efetuar escolhas conscientes relativas à administração de seus recursos;

- Contribuir para a eficiência e solidez dos mercados financeiro, de capitais, de seguros, de previdência e de capitalização (O QUE É, 2012).

Os objetivos contemplam, pois, diferentes níveis, englobando interesses coletivos (país), pessoais (cidadão) e de mercado financeiro, de capitais, de seguros, de previdência e de capitalização. Especificamente no espaço escolar, espera-se que o uso de ferramentas financeiras favoreça um maior planejamento dos alunos, fazendo com que os pais também sejam influenciados pela proposta (EDUCAÇÃO, 2011). Conforme afirma o site oficial do programa, materiais didáticos também serão utilizados, e outros aspectos, além do exclusivamente financeiro, serão considerados, como é o caso da Responsabilidade Socioambiental (EDUCAÇÃO, 2011). Essa seria uma das contribuições das instituições envolvidas para o 
desenvolvimento sustentável, estratégia que se soma a outras ações em princípio já presentes no mercado financeiro, entre as quais a avaliação das variáveis social e ambiental nas operações de crédito e nos investimentos (LIMA, 2009).

A crise global recente e a concepção do Programa ENEF, iniciativa conjunta do poder público e da iniciativa privada, indicam que a questão financeira não diz respeito tão somente à esfera individual ou familiar, ou à esfera produtiva, ou ao "Governo", ou ao mercado financeiro, mas a todos conjuntamente. Indicam, além disso, que a questão financeira tem amplas implicações sociais. Por isso, acreditamos que a educação financeira, no âmbito escolar, é de fato algo desejável, desde que seu objetivo seja levar à compreensão básica do funcionamento do sistema financeiro e permitir ao educando reconhecer possibilidades e limites desse sistema. Isso significaria favorecer não só o desenvolvimento da capacidade do aluno de "planejar, decidir e avaliar as consequências de suas escolhas [financeiras] no longo prazo" (CORONATO, 2011), mas também de uma visão crítica desse sistema, aspecto este provavelmente pouco enfatizado no programa, conforme sugerem os seus objetivos, acima citados.

Em suas diversas vertentes, a Educação Matemática, enquanto campo de investigação científica, tem fornecido bases para discussões que visam à superação da "relação antagônica entre a matemática do cotidiano e a matemática escolar" (HOFMANN; MORO, 2012). Nesse sentido, diversos estudos realizados, no âmbito desse campo, têm enfatizado a importância do ensino da Matemática relacionado a situações do cotidiano que envolvem aspectos econômico-financeiros, a fim de favorecer a tomada de decisões de consumo conscientes e cidadãs. ${ }^{10}$

No entanto, embora reconheçamos o importante avanço que essa perspectiva representa, defendemos que a educação financeira se insira no contexto mais amplo do consumo responsável, o que implica situála em sua relação com os outros vértices implicados no consumo, os quais, grosso modo, podem ser reunidos sob o rótulo responsabilidade socioambiental, ${ }^{11}$ para utilizar o termo usado pelo programa ENEF. Uma possível queda nos juros propiciaria maior consumo e, portanto, evidenciaria ainda mais a necessidade de educar para o consumo responsável, ou seja, uma educação visando a propiciar ao aluno elementos que permitam a ele exercer o papel de consumidor como exercício do "aperfeiçoamento na utilização de bens e serviços de empresas ou indivíduos, respeitan- 
do-se princípios que objetivem a manutenção ou restauração do bemestar coletivo e individual" (SALEH; SALEH, 2010).

A aplicação dessa definição, considerando seus desdobramentos, permite esclarecer situações práticas, relativas ao consumo, e cotidianamente conhecidas. Assim, ela pode ser útil ao consumidor que não só deseja construir e manter a sua saúde financeira, mas também almeja para si uma conduta cidadã, distinguindo e escolhendo profissionais, empresas ou fornecedores que respeitem princípios de um consumo responsável. Nessa perspectiva, as estratégias e implicações financeiras envolvidas na compra do produto ou serviço devem ser analisadas em conjunto com os diversos aspectos envolvidos no consumo, os quais incluem a esfera do meio ambiente, da publicidade, da saúde e da segurança, do direito e da ética (ver FIGURA 1).

O consumo pensado a partir desses múltiplos fatores é evidenciado pela coleção Educação para o consumo responsável, elaborada pelo IDEC (Instituto de Defesa do Consumidor) e pelo Inmetro (Instituto Nacional de Metrologia, Normalização e Qualidade Industrial), com a finalidade de fornecer subsídios para a abordagem do tema no ensino básico. Conforme explicitado na sua apresentação, o material foi produzido tendo como referência os Parâmetros Curriculares Nacionais (PCNs), mais especificamente na seção Trabalho e Consumo, inserida nos Temas Transversais (Meio Ambiente, Saúde, Pluralidade Cultural, Orientação Sexual, Trabalho e Consumo, e Ética), e dirigido a professores e alunos do terceiro e quarto ciclos do Ensino Fundamental (BRASIL, 1998). Os títulos da coleção nomeiam os componentes considerados fundamentais na educação para o consumo responsável: Meio Ambiente (INMETRO; IDEC, 2002a), Saúde e Segurança (INMETRO; IDEC, 2002b), Publicidade (INMETRO; IDEC, 2002c) e Direito e Ética (INMETRO; IDEC, 2002d).

Recentemente, com o intuito de contribuir para o desenvolvimento de uma visão crítica acerca do consumo responsável, propusemos um modelo de "Educação para o Consumo Responsável" (ECR), em forma de fluxograma (FIGURA 1), que buscou representar as diretrizes apontadas na coleção e explicitar a inter-relação desses diversos aspectos, sugerindo uma possível forma de analisar e sistematizar a questão do consumo (SALEH, 2010; SALEH; SALEH, 2010; SALEH; SALEH, 2012), a partir da observação dos papéis desempenhados pelas empresas, produtos e serviços. 
FIGURA 1 - Modelo descritivo da "Educação para o Consumo Responsável" (ECR), que envolve as vertentes: (1) e (2) - Meio Ambiente; (3) e (6) Saúde e Segurança; (4) Publicidade; (1) - (6) Direito e Ética. Ao contrário dos trabalhos anteriores, por uma questão de abrangência, desmembramos o Direito e a Ética em duas vertentes distintas. Ou seja, aqui estamos considerando cinco vertentes:

Meio Ambiente, Saúde, Publicidade, Direito e Ética.

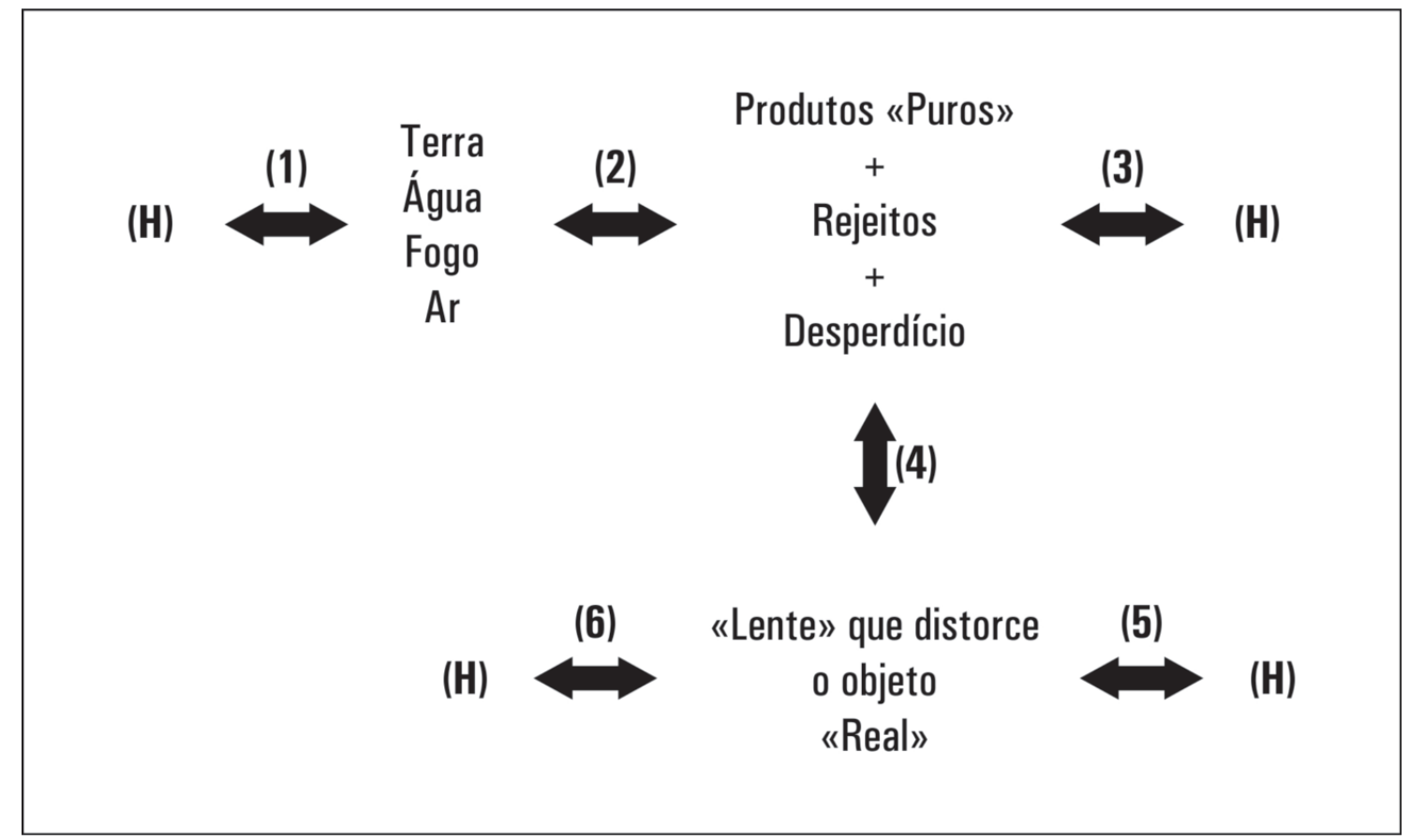

FIGURA 2 - Indica 0 aspecto financeiro da "Educação para o Consumo Responsável" (ECR) e corresponde à equação PreçoECR. As vertentes da FIGURA 1 compõem os preços individuais - pontas da estrela - da equação Preçoecr.

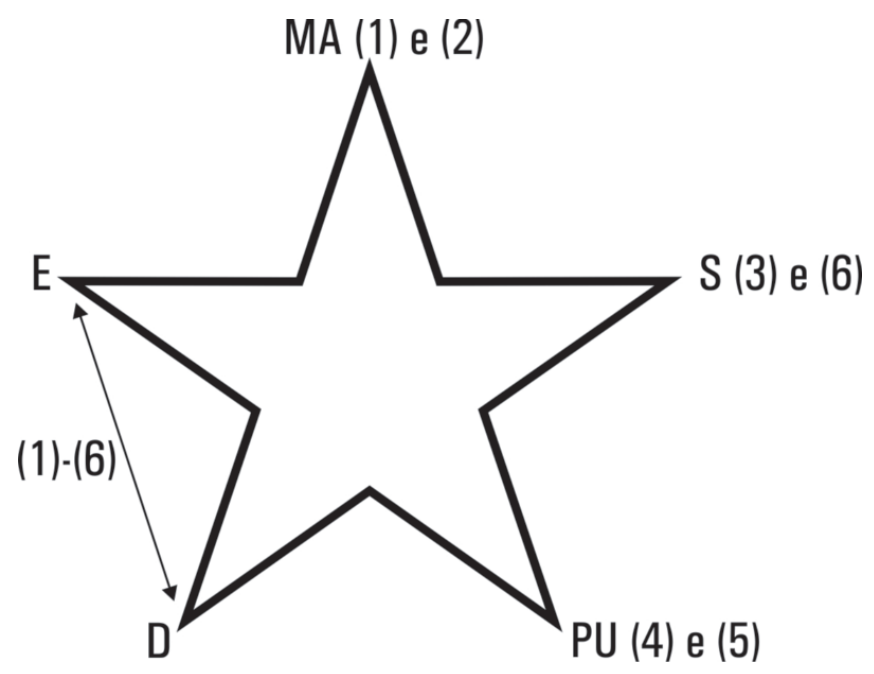


No entanto, como o leitor terá observado, a coleção e, consequentemente, o fluxograma acima não dedicam um fascículo específico ao aspecto financeiro, o que acaba por colocá-lo em segundo plano na abordagem do tema, ainda que praticamente todos os fascículos o contemplem de alguma forma. Além das questões conjunturais que permeiam o nosso dia a dia, influenciando fortemente o universo financeiro e o consumo, sabe-se que as decisões que envolvem a aquisição de um produto ou serviço são igual e intensamente influenciadas pelo preço (GALVÃO, 2009).

Há uma definição típica para o preço (SANTOS, 1986), que envolve custos de produção (matéria-prima, fabricação e mão de obra), despesas de natureza administrativa e financeira e os lucros obtidos. No entanto, aqui propomos uma segunda forma de expressar o preço:

$$
\operatorname{PreçoEcr}=\operatorname{Preço1}(\mathrm{MA})+\operatorname{Preço2}(\mathrm{S})+\operatorname{Preç03}(\mathrm{Pu})+\operatorname{Preço4}(\mathrm{D})+\operatorname{Preç05}(\mathrm{E})
$$

\section{Em que:}

Preçoech é igual à somatória de preços individuais (Preç01,2,3,4,5), mostrados como "pontas da estrela", na FIGURA 2, e relacionam-se às vertentes MA (Meio Ambiente), S (Saúde e Segurança), Pu (Publicidade), D (Direito) e E (Ética).

Essa forma de apresentar o preço é mais coerente com as análises dos quatro exemplos que desenvolveremos a seguir, que envolvem tanto o aspecto financeiro como o do consumo responsável (ou não). Assim, cada exemplo se associará a um ou mais termos da equação Preçoecr.

O preço, elemento financeiro chave do consumo por exercer papel central em eventos de compra e venda do nosso cotidiano, decorre de uma série de fatores relacionados aos aspectos reconhecidamente pressupostos no consumo responsável, mas nem sempre isso é percebido pelo consumidor. Não pode ser considerado responsável o consumo guiado apenas pelo preço e/ou pelas possibilidades financeiras pessoais; mas também não pode ser responsável o consumo guiado pelos aspectos previstos na coleção - meio ambiente, saúde e segurança, publicidade, direito e ética - sem reconhecer o devido papel do aspecto financeiro.

São muitos os dados do cotidiano que nos permitem levantar elementos em defesa de uma educação para o consumo que não coloque 
o aspecto financeiro nem como prioritário, como no programa ENEF, nem como secundário, como na coleção do IDEC e do Inmetro, mas no mesmo patamar que os demais aspectos. Embora os fascículos da coleção forneçam diversos exemplos que poderiam ser reanalisados para evidenciar a importância do aspecto financeiro na sua relação com a multiplicidade de elementos envolvidos em situações reais ou potenciais de consumo, não os retomaremos aqui, pois nos parece mais interessante explorar exemplos mais recentes.

\section{Situaç̃̃es relacionadas ao consumo: breve análise}

Antes de iniciarmos a análise, vale lembrar que, embora as situações de aquisição de bens e serviços sejam sempre complexas do ponto de vista do consumo responsável, obviamente nem todas envolvem diretamente as cinco vertentes reconhecidas na nossa proposta. Além disso, não é nosso objetivo exaurir todos os elementos passíveis de serem contemplados na análise de cada exemplo, mas chamar a atenção para a com-

plexidade envolvida nos processos de consumo. Feitas essas ressalvas, passemos ao primeiro exemplo.

\section{Exemplo 1 - Entre 2006 e 2013, 0 aumento de preços dos alimentos e bebidas no Brasil foi de $79 \%$}

"Em 12 meses, a inflação dos alimentos e bebidas subiu 11,4\%. No acumulado de sete anos (de julho de 2006 a julho de 2013), os preços desse grupo subiram $79 \%$, ainda que, nesse intervalo de tempo, tenha havido oscilações, segundo a Tendências Consultoria" (EM SETE ANOS, 2013). Os eventos climáticos extremos, em vários países, a dolarização de alguns insumos, como adubo e ração, e problemas de safra são alguns dos responsáveis pelo aumento de preços observado (QUAINO, 2013).

Trata-se de um bom exemplo porque evidencia diversos vértices pressupostos no consumo: a questão ambiental e a financeira são óbvias, mas há que se considerar também a questão da saúde e da ética. São os mais pobres os mais afetados pelo aumento dos preços de alimentos, uma vez que os gastos com alimentação representam boa parte do seu orça- 
mento. Há que se considerar que prejuízo na alimentação leva a prejuízo na saúde e, consequentemente, na produtividade do trabalhador e da trabalhadora. Toda a situação levanta uma questão ética por envolver o problema de destinação das terras produtivas, o consumo exagerado de alimentos por quem pode pagar por eles, bem como o desperdício tanto no processo de produção como no consumo. Envolve, em resumo, a necessidade de políticas nacionais e globais de combate à pobreza.

\section{Exemplo 2 - Consultas médicas em curtíssimo tempo no serviço público ou privado}

Esse exemplo refere-se a uma situação que, atualmente, é quase regra no setor: consultas médicas realizadas em curtíssimo tempo, seja no serviço público ou privado. Conforme podemos perceber, no dia a dia, e a mídia tem denunciado (OLIVEIRA; GOMES, 2011), há ocorrências de consulta de três minutos. Apesar de o tempo de atendimento variar de acordo com o caso, o protocolo de uma consulta médica inclui conversar com o paciente para identificar queixas e seu histórico clínico e familiar, realizar exames físicos, solicitar exames nos casos em que se fizer pertinente. Obviamente, não é possível cumpri-lo em tão pouco tempo, tendendo-se a ignorar os dois primeiros procedimentos e priorizar o terceiro.

Se a dimensão da ética e da saúde estão aí claramente presentes, implicadas não só na relação médico-paciente, mas no sistema de saúde como um todo, podemos também reconhecer facilmente as consequências financeiras desse tipo de procedimento. Aumenta-se o custo, seja público ou privado, com exames, não só porque eles são solicitados em casos em que não seriam necessários, mas também porque, por não partirem de indícios coletados nas outras duas etapas, não condizem com as necessidades do quadro clínico do paciente; com as próprias consultas, já que o paciente terá de voltar mais vezes ao médico; com deslocamento para as consultas e para a realização dos exames; com medicamentos, uma vez que são prescritos remédios que também não condizem com o real problema de saúde; com internações, considerando-se que o diagnóstico equivocado e/ou a demora no diagnóstico podem levar ao agravamento da moléstia, exigindo um cuidado mais intenso. Do ponto de vista financeiro, sem levar em conta os casos extremos de óbito, que, muitas vezes, prejudicam as finanças familiares, há que se considerar ainda as perdas de 
produtividade, tanto pelo problema de saúde em si, como pelo tempo gasto nas idas e vindas. Não é possível ignorar também a questão ambiental, implicada em diversos dos elementos acima, por isso, chamamos a atenção, especialmente, para a produção e descarte dos medicamentos e seus invólucros, o que, na maioria das vezes, é realizado de forma inadequada.

Consideremos agora o terceiro exemplo.

\section{Exemplo 3 - Normas para a publicidade que contenha apelos de sustentabilidade}

Em junho de 2013, o CONAR - Conselho Nacional de Autorregulamentação Publicitária - criou novas normas para a publicidade que contenha apelos de sustentabilidade. Segundo o site do referido Conselho:

O sentido geral das novas normas é reduzir o espaço para usos do tema sustentabilidade que, de alguma forma, possam banalizá-lo ou confundir os consumidores. Além de condenar todo e qualquer anúncio que estimule o desrespeito ao meio ambiente, o Código recomenda que a menção à sustentabilidade em publicidade obedeça estritamente a critérios de veracidade, exatidão, pertinência e relevância.

Um anúncio que cite a sustentabilidade deve, assim, conter apenas informações ambientais passíveis de verificação e comprovação, que sejam exatas e precisas, não cabendo menções genéricas e vagas. As informações devem ter relação com os processos de produção e comercialização dos produtos e serviços anunciados e o benefício apregoado deve ser significativo, considerando todo seu ciclo de vida (O CONAR, 2011).

A necessidade de estabelecer normas para a publicidade que contenha apelo à sutentabilidade decorreu, como sugere o texto acima (e certamente os usuários dos meios de comunicação mais atentos puderam perceber), do abuso no uso do tema no setor. Ou seja, a publicidade de produtos e serviços sem técnicas que favorecessem a qualidade de vida e o meio ambiente apresentava-os como se tivessem sido produzidos com essa preocupação e com os cuidados que ela demanda. A regulamentação teve, portanto, uma motivação legal e ética.

Vale observar, porém, que a publicidade está diretamente relacionada ao aspecto financeiro, pois é uma forma de agregar valor à marca e, pois, ao produto ou serviço, uma vez que os torna conhecidos e alme- 
jados pelo público. Portanto, a escolha dos temas dos anúncios é fundamental para fixar uma marca, condição que possibilita um preço diferenciado no mercado. Ou seja, as pessoas precisam não só conhecer a marca, mas também acreditar que vale a pena pagar o preço do produto. No entanto, nem sempre a compra pela marca está atrelada a um preço justo, considerando-se a qualidade do produto (INMETRO; IDEC, 2002c). Uma empresa que procura vincular sua marca à sustentabilidade visa a atingir consumidores que se preocupam com a questão ambiental e que, não raro, se dispõem a pagar um pouco mais por produtos e serviços que, em tese, produzem menos impacto no meio ambiente. Vemos, então, que a diferença entre o valor pago e o valor razoavelmente esperado pelo produto pode trazer prejuízos ao consumidor. É interessante observar que é difícil identificar uma conduta imprópria de uma dada empresa, pois, muitas vezes, as técnicas de publicidade são variadas e sofisticadas, jogando com sentidos ambíguos que se constroem não só a partir da linguagem verbal, mas de diferentes semioses.

Passemos agora ao último exemplo de que nos ocuparemos nesta ocasião.

\section{Exemplo 4 - Mão de obra escrava no mercado da moda}

Uma outra situação aparentemente menos abrangente diz respeito à utilização de mão de obra escrava, seja diretamente pela empresa envolvida, seja por empresas que adquirem produtos que, em algum momento da cadeia produtiva, envolvem mão de obra escrava. A maioria dos casos identificados no Brasil é do setor de agronegócios. No entanto, traremos aqui, por serem recentes e de grande repercussão na mídia, dois casos que envolveram a indústria têxtil - Lojas Marisa (HASHIZUME, 2010), no ano de 2010, e a empresa espanhola Inditex (uma das maiores varejistas do mundo da moda), dona da marca Zara, no ano de 2011 (OSCAR, 2011). Ambas contrataram fornecedores que terceirizavam a produção, usando trabalho escravo de imigrantes sul-americanos, realizado em condições bastante precárias de higiene e de segurança. $\mathrm{O}$ trabalho escravo é uma questão legal e ética, frequentemente também de saúde e segurança, como os casos acima, mas que tem implicações financeiras, já que possibilita um preço menor do que o de produtos similares ou que não seja condizente com o seu custo real. 
Embora seja sempre possível e, às vezes, necessário fazer recortes para evidenciar um ou outro aspecto envolvido nas situações de consumo, a análise desses eventos do cotidiano nos permite mostrar que se trata de um processo que envolve uma boa dose de complexidade. Também nos permite evidenciar que considerar outros elementos, além do financeiro, ao se efetuar uma compra, demanda um entendimento do consumo que envolve fatores não apenas individuais e familiares, mas uma visão mais global e crítica do processo de produção e da sociedade em geral.

\section{Consumo, educação, desenvolvimento da autonomia e ética}

Adotar essa visão de consumo como objeto de ensino formal é, antes de tudo, assumir o sentido de educação como prática que visa ao desenvolvimento da autonomia dos educandos, reconhecendo-os, na esteira do grande educador Paulo Freire, como seres gestados "socialmente na história" (FREIRE, 2011, p.20), inconclusos e curiosos, que conhecem o mundo na medida em que nele intervêm, transformando, nesse processo, a curiosidade ingênua em curiosidade crítica, epistemológica.

Isso implica a necessidade de o educador também assumir-se como ser inacabado, como presença no mundo que se reconhece a si mesmo a partir do outro, o que o impede de se colocar na posição de "observador imparcial, objetivo, seguro, dos fatos e dos acontecimentos" (FREIRE, 2011, p.16). Esse modo de conceber o ser humano coloca a ética no centro do pensamento freiriano: enquanto "presença que se pensa a si mesma, que se sabe presença, que intervém, que transforma, que fala do que faz mas também sonha, que constata, compara, avalia, valora, que decide, que rompe" (FREIRE, 2011, p.20), não é possível ao ser humano fugir à responsabilidade ética no seu mover-se no mundo. Nesse contexto, a educação visa à mudança e não à adaptação:

Como subjetividade curiosa, inteligente, interferidora na objetividade com que dialeticamente me relaciono, meu papel no mundo não é só o de quem constata o que ocorre, mas também o de quem intervém como sujeito de ocorrências. Não sou apenas objeto da História, mas seu sujeito igualmente. No mundo da História, da cultura, da política, constato não para me adaptar, mas para mudar (FREIRE, 2011, p.74-75) (Grifos do autor). 
Nas análises anteriores, assim como no modelo apresentado (FIGURAS 1 e 2), a ética é uma dentre as diversas facetas implicadas no consumo. No entanto, ao tomarmos o ser humano como "presença que se pensa a si mesma", torna-se explícito que o fio que permeia o nosso olhar de sujeito para todos os aspectos do consumo é a dimensão ética, o que evidencia o consumo como um ato que implica, necessariamente, responsabilidade, da qual não podemos escapar. De fato, como insiste Paulo Freire, "não posso me perceber como presença no mundo, mas, ao mesmo tempo, explicá-la como resultado de operações absolutamente alheias a mim" (FREIRE, 2011, p.53).

Dessa forma, com esse educador, observamos que, enquanto sujeitos da história, não só nossos atos individuais devem ser pautados pela ética, mas também a ação da sociedade no cotidiano deve ser, de nossa parte, objeto de uma avaliação ética e, portanto, responsável. Isso implica pensar o consumo como um complexo processo, e, portanto, a educação para o consumo, numa perspectiva que evidencie as suas múltiplas dimensões, condição para a constituição de subjetividades que, por meio de suas decisões de consumo, possam se situar e intervir eticamente em um mundo em que prevalecem os interesses do mercado.

\section{Considerações finais}

O senso comum, muitas vezes presente também na escola, considera que o conhecimento necessário para a educação financeira é o da matemática e, em especial, o da matemática financeira (porcentagem, juros simples e compostos etc), reduzindo-a a uma questão meramente quantitativa e individual/familiar. A Educação Matemática tem avançado na formulação de elementos conceituais e metodológicos que contribuem para a superação da dicotomia entre a matemática do cotidiano e a matemática escolar (HOFMANN; MORO, 2012), mas mantém, em linhas gerais, a especificade do campo.

De nossa parte, colocamos em relevo que, em termos de educação, a questão financeira deve ser situada no âmbito do consumo responsável. Diante disso, procuramos, neste texto, evidenciar que a questão financeira está presente de diversas formas no nosso cotidiano e que as finanças pessoais estão cada vez mais atreladas ao que acontece na econo- 
mia do Brasil e do mundo, mas tem igualmente amplas implicações sociais.

As quatro situações, extraídas da mídia e por nós aqui tomadas como dados para análise, exemplificam ocorrências da predominância de cada uma das vertentes - Meio Ambiente, Saúde e Segurança, Publicidade e Direito e Ética - inicialmente reconhecidas pela ECR na coleção do Inmetro e do IDEC e por nós assumidas em trabalhos anteriores sobre o tema (SALEH, 2010, SALEH; SALEH, 2010; SALEH; SALEH, 2012). Ressaltamos a inter-relação dessas diversas facetas, mas procuramos avançar em relação a esse modelo inicial, na medida em que reconhecemos a presença do aspecto financeiro como um elemento que tem fortes relações com todos os aspectos do consumo. Foi essa compreensão que nos levou a rever o nosso modelo descritivo, em forma de fluxograma, para incluirmos o elemento financeiro no âmbito da educação para o consumo responsável.

Nesse sentido e tendo em mente o ENEF, defendemos, assim como o referido programa, a educação financeira no âmbito escolar, mas entendemos que ela deve permitir não só a compreensão básica do funcionamento do sistema financeiro, mas também possibilitar ao educando reconhecer possibilidades e limites desse sistema. Ou seja, não se trata apenas de capacitar o aluno para lidar com as ferramentas financeiras presentes em seu cotidiano, mas também de desenvolver uma visão crítica desse sistema, objetivo este não incluído no referido programa. Para atingi-lo, acreditamos que seja necessário reconhecer a especificidade do financeiro, mas também a sua inter-relação com os outros vértices implicados no consumo responsável, numa perspectiva necessariamente multidisciplinar.

Pensar o consumo dessa forma é assumi-lo como uma maneira de intervir no mundo (FREIRE, 2011), portanto, sua inserção como objeto de ensino formal só pode se dar no interior de uma prática cujo fim é o desenvolvimento da autonomia dos alunos. Essa visão nos levou ao reconhecimento da dimensão ética, presente no modelo inicial, mas reinterpretada de acordo com o pensamento de Paulo Freire, como o elemento que permeia e relaciona entre si todos os aspectos referentes ao consumo. Isso nos permitiu (re)defini-lo como um ato que implica, acima de tudo, responsabilidade, já que somos "presença que se pensa a si mesma". 


\section{NOTAS}

1 Commodities são produtos com baixo grau de industrialização ligados à energia (por exemplo, o petróleo, o gás natural), metais (por exemplo, o ouro, a prata), agricultura (por exemplo, a soja, o trigo e o milho), carne e pecuária (por exemplo, os bovinos e o gado leiteiro), e os de consumo (por exemplo, o café, o açúcar). Disponível em: $<$ http://money.cnn.com/data/commodities/?iid=MK'T_Sub>. Acesso em: 03 abr. 2012.

2 Subprime "É um crédito de risco, concedido a um tomador que não oferece garantias suficientes para se beneficiar da taxa de juros mais vantajosa (prime rate)." Especificamente, "o termo designa uma forma de crédito hipotecário (mortgage) para o setor imobiliário, surgida nos Estados Unidos e destinada a tomadores de empréstimos que representam maior risco." Disponível em: <http://pt.wikipedia.org/wiki/Subprime>. Acesso em: 23 abr. 2012.

3 A dívida pública é a soma total de todos os empréstimos feitos pelo governo junto a credores (privados ou não, nacionais ou internacionais) (ARBEX JÚNIOR, 2011). Essa dívida visa a financiar gastos não cobertos pela arrecadação de impostos e vincula-se, como mencionamos no texto, aos rombos estatizados pelos governantes.

4 O PIB (Produto Interno Bruto) é a soma total, em valores monetários, de todos os bens e serviços produzidos ao longo do ano (ARBEX JÚNIOR, 2011) e depende essencialmente do consumo das famílias, do investimento das empresas, gastos do governo e do setor externo.

5 Os lucros dos bancos, em 2011, foram, em R $\$$ mil, aproximadamente: 1) Banco do Brasil (Público Federal) - R \$ 6.000.000; 2) Itaú (Privado, Nacional, que integra o conglomerado Itaú Unibanco e participa, por meio de seu Instituto, da Estratégia Nacional de Educação Financeira - ENEF) - R \$ 7.500.000; 3) Bradesco (Privado, Nacional) R\$ 5.500.000; 4) Banco Nacional de Desenvolvimento Econômico e Social - BNDES - Público Federal) - R\$ 3.800.000; 4) Caixa Econômica Federal - CEF - Público Federal) - R $\$ 2.900 .000$; 5) Santander (Privado, Controle Estrangeiro) - R \$ 1.800 .000 (FEBRABAN, 2012).

6 Essa informação foi obtida em um jornal de grande circulação, pois ainda não se encontra disponível no site do IBGE

(http://www.ibge.gov.br/home/estatistica/pesquisas/pesquisa_resultados.php?id_pesq uisa=5).

7 Autarquia é "serviço estatal descentralizado e com autonomia econômica, embora tutelado pelo poder público” (SANDRONI, 1999, p.36). As autarquias envolvidas são:

- Banco Central do Brasil - vinculada ao Ministério da Fazenda, responsável pela formulação, execução, acompanhamento e controle das políticas monetária, cambial, de crédito e de relações financeiras com o exterior, regulando e fiscalizando o Sistema Financeiro Nacional; - Comissão de Valores Mobiliários - CVM - coordenadora da Estratégia Nacional de Educação Financeira - ENEF, vinculada ao Ministério da Fazenda, responsável pela fiscalização e regulação do mercado de valores mobiliários; 
- Superintendência Nacional de Previdência Complementar - vinculada ao Ministério da Previdência, responsável pela supervisão e fiscalização das entidades fechadas de previdência complementar, conhecidas como fundos de pensão;

- Superintendência de Seguros Privados - SUSEP - vinculada ao Ministério da Fazenda, responsável pelo controle e fiscalização dos mercados de seguro, previdência privada aberta, capitalização e resseguro (INSTITUIÇÕES, 2012).

8 ANBID (Associação Nacional dos Bancos de Investimento), ANDIMA (Associação Nacional das Instituições do Mercado Aberto), FENAPREVI (Federação Nacional de Previdência Privada e Vida), FENASEG (Federação Nacional das Empresas de Seguros Privados e Capitalização) etc. (INSTITUIÇÕES, 2012).

9 BM\&FBOVESPA "é uma companhia que administra mercados organizados de títulos, valores mobiliários e contratos derivativos, além de prestar serviços de registro, compensação e liquidação, atuando, principalmente, como contraparte central garantidora da liquidação financeira das operações realizadas em seus ambientes" (BM\&FBOVESPA, 2013).

10 Essa perspectiva está presente, por exemplo, em Hofmann e Moro (2012) e Kistemann Júnior (2011), os quais apresentam também uma revisão de literatura sobre o tema. Outra referência interessante e não citada pelos referidos autores é Fiel (2005), que aborda uma ligação entre Educação Matemática e cidadania, focando o ensino de Matemática Financeira fundamentado na perspectiva da etnomatemática.

11 Apesar de o termo aparecer no site oficial do programa, os objetivos ali explicitados não contemplam nenhum aspecto que diga respeito à questão ambiental.

\section{REFERÊNCIAS}

ARBEX JÚNIOR, J. Tempos de crise: a tempestade se avizinha. Caros Amigos, São Paulo, ano XV, n.172, p.8-9, jul. 2011. Disponível em:

$<$ http://www.controversia.com.br/index.php?act=textos\&id=9411>. Acesso em: 05 set. 2011.

BAIXA renda chega a 61\% do varejo on-line. Diário Comércio e Indústria, São Paulo, 03 ago. 2011. Disponível em: <http://www.dci.com.br/Baixa-renda-chega-a-61_-do-varejo-on-line-11-383915.html>. Acesso em: 04 mar. 2012.

BASTOS, C. Consumo de bens duráveis aumenta por causa do Bolsa Família. Ministério do Desenvolvimento Social e Combate à Fome, DF, 22 fev. 2008. Disponível em: <http://www.mds.gov.br/noticias/consumo-de-bens-duraveis-aumenta-por-causa-dobolsa-familia>. Acesso em: 02 maio 2011.

BM\&FBOVESPA: a nova bolsa. Disponível em: <http://www.bmfbovespa.com.br/ptbr/intros/intro-sobre-a-bolsa.aspx?idioma=pt-br>. Acesso em: 08 set. 2013.

BRASIL. Presidência da República. Casa Civil. Subchefia para assuntos jurídicos.

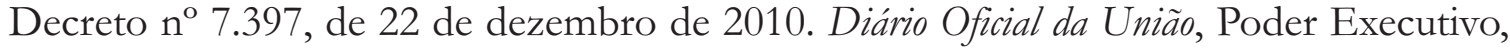
Brasília, DF, 23 dez. 2010. Seção 1, Edição Extra, p.7. Disponível em: 
<http://www.planalto.gov.br/ccivil_03/_Ato2007-2010/2010/Decreto/D7397.htm>. Acesso em: 06 fev. 2012.

BRASIL. S.E.F. Parâmetros Curriculares Nacionais: terceiro e quarto ciclos: apresentação dos temas transversais. Brasília, DF, 1998.

BRESSER-PEREIRA, L. C. A crise financeira e depois: um novo capitalismo? Novos estudos - CEBRAP, São Paulo, n.86, mar. 2010. Disponível em:

<http://www.scielo.br/pdf/nec/n86/n86a03.pdf>. Acesso em: 03 maio 2011.

CLASSE C usa mais cartões. Avenida Brasil Comunicaşão, 29 abr. 2009. Disponível em: $<$ http://marketingmax.wordpress.com/2009/04/29/avenida-brasil-comunicacao-classe-c-usa-mais-cartoes/>. Acesso em: 24 set. 2011.

COLELLO, S. M. G. A pedagogia da exclusão no ensino da língua escrita. 2003. Disponível em: <http://www.hottopos.com/videtur23/silvia.htm>. Acesso em: 27 set. 2013.

CORONATO, M. O que as escolas vão ensinar sobre dinheiro. Curitiba, 11 jan. 2011. Disponível em:

$<$ http:/ / www.jusprev.org.br/site/index.php?option=com_content\&view $=$ article\&id $=5$ 84:o-que-as-escolas-vao-ensinar-sobre-dinheiro\&catid $=1$ :destaques $\&$ Itemid $=18>$. Acesso em: 06 fev. 2012.

D’AGOSTO, M. Até quanto sobe a Selic? Valor, São Paulo, 12 jun. 2013. Disponível em: $<$ http://www.valor.com.br/valor-investe/o-consultor-financeiro/3154046/ate-quantosobe-selic >. Acesso em: 12 jun. 2013.

DOMINGOS, J. Lula envia a Obama sugestões para lidar com a crise. O Estado de São Paulo, São Paulo, 30 nov. 2008. Internacional, p.21.

DPSP - Defensoria Pública de São Paulo. Procon - Defensoria Pública: superendividados terão ajuda para sair do vermelho. Correio Forense: a justiça do Direito on-line, 02 fev. 2010. Disponível em:

<http://www.correioforense.com.br/noticia/idnoticia/52598/titulo/ProconDefensoria_ Publica_Superendividados_terao_ajuda_para_sair_do_vermelho.html $>$. Acesso em: 02 maio 2011.

EDUCAÇÃO Financeira nas Escolas. Vida \& dinheiro: educação financeira. Disponível em: <http://www.vidaedinheiro.gov.br/EducacaoFinanceira/Default.aspx>. Acesso em: 03 maio 2011.

EM SETE ANOS, o preço dos alimentos subiu 79\%. O Economista, 08 ago. 2013. Disponível em: <http://www.oeconomista.com.br/em-sete-anos-preco-dos-alimentossubiu-79/>. Acesso em: 06 set. 2013.

FEBRABAN. Balanço consolidado. Série histórica. Disponível em: <http://www.febraban.org.br/bd/>. Acesso em: 18 abr. 2012.

FIEL, M. V. Um olhar para o elo entre educação matemática e cidadania: a matemática financeira sob a perspectiva da etnomatemática. 87f. 2005. Dissertação (Mestrado Profissional em Ensino de Matemática) - Centro de Ciências Exatas e Tecnologias, PUC-SP, São Paulo, 2005.

FREIRE, P. Pedagogia da autonomia. 43.ed. São Paulo: Paz e Terra, 2011.

FRIAS, M. C. Crise faz despertar debate sobre Keynes. Folha de São Paulo, São Paulo, 29 dez. 2008. Folha Invest, p.5.

GALVÃO, A. IPI continua menor só para eletrodomésticos “verdes”. Valor, São Paulo, 
30 out. 2009, p.3. Disponível em:

< http://www2.senado.gov.br/bdsf/bitstream/id/175178/1/noticia.htm>. Acesso em: 23 set. 2011.

GIANNETTI, E. Felicidade: diálogos sobre o bem-estar na civilização. São Paulo: Companhia das Letras, 2002.

GODOY, J.; MEDINA, L. G.; GAZZEL JÚNIOR, M. A. Investindo em ações: os primeiros passos. 2.ed. São Paulo: Saraiva, 2006.

HALFELD, M. Atual crise financeira internacional não tem solução fácil. Rádio $C B N$, São Paulo, 09 ago. 2011. Disponível em: <http://cbn.globoradio.globo.com/comentaristas/mauro-halfeld/2011/08/09/ATUAL-CRISE-FINANCEIRA-INTERNACIONAL-NAO-TEM-SOLUCAO-FACIL.htm>. Acesso em: 09 set. 2011.

HASHIZUME, M. Escravidão é flagrada em oficina de costura ligada à Marisa. Repórter Brasil: agência de notícias, 17 mar. 2010. Disponível em:

<http:/ /www.reporterbrasil.org.br/exibe.php?id=1714>. Acesso em: 10 maio 2012.

HISTÓRICO das taxas de juros. Disponível em: <http://www.bcb.gov.br/?COPOMJUROS>. Acesso em: 05 set. 2013.

HOFMANN, R; MORO, M. L. F. Educação matemática e educação financeira: perspectivas para a ENEF. Zetetiké, Campinas, v.20, n.38, p.37-54, jul./dez. 2012.

INMETRO; IDEC. Meio ambiente e consumo: coleção educação para o consumo responsável. São Paulo: Idec, 2002a.

INMETRO; IDEC. Saúde e segurança do consumidor: coleção educação para o consumo responsável. São Paulo: Idec, 2002b.

INMETRO; IDEC. Publicidade e consumo: coleção educação para o consumo responsável. São Paulo: Idec, 2002c.

INMETRO; IDEC. Direitos do consumidor e ética no consumo: coleção educação para o consumo responsável. São Paulo: Idec, 2002d.

INSTITUIÇÕES Envolvidas. Vida \& dinheiro: educação financeira. Disponível em: <http://www.vidaedinheiro.gov.br/Instituicoes/Default.aspx>. Acesso em: 07 fev. 2012.

JÚNIOR, C. 12\% das famílias devem 5 vezes a sua renda. Folha de São Paulo, São Paulo, 01 set. 2010. Caderno Mercado, p.4.

KISTEMANN JÚNIOR, M. A. Sobre a produção de significados e a tomada de decisão de indivíduos-consumidores. 528 f. 2011. Tese (Doutorado em Educação Matemática) - Instituto de Geociências e Ciências Exatas, Universidade Estadual Paulista, Rio Claro, 2011.

LEGISLAÇÃO. Vida \& dinheiro: educação financeira. Disponível em:

<http://www.vidaedinheiro.gov.br/Legislacao/Default.aspx>. Acesso em: 07 fev. 2012. LEITÃO, M. As previsões do Banco Central. Radio CBN, São Paulo, 30 set. 2011. Disponível em: <http:/ / cbn.globoradio.globo.com/Player/playerOndemand.htm?audio $=2011 \% 2 \mathrm{Fcolu}$ nas $\% 2$ Fmleitao_110930\&OAS_sitepage $=\mathrm{cbn} /$ comentarios $/$ miriamleitao $\% 2$ Fplayer $>$. Acesso em: 30 set. 2011.

LIMA, S. A. S. Banco Central e responsabilidade social. Boletim Responsabilidade Social e Ambiental do Sistema Financeiro, Brasília, DF, ano 4, n.38, jan. 2009. Disponível em: <http://www.bcb.gov.br/pre/boletimrsa/BOLRSA200901.pdf>. Acesso em: 30 jan. 2012. 
LOYOLA, G. Crédito: política equivocada fragiliza bancos. Valor, São Paulo, 02 fev. 2009. p.13. Disponível em: <http://aurora.proderj.rj.gov.br/resenha/resenha-imagens/2009-02-02_89.PDF>. Acesso em: 23 set. 2011.

MANIR, M. Sempre alerta. O Estado de São Paulo, São Paulo, 29 nov. 2008. Caderno Aliás, p.4. Disponível em: <http://www.estadao.com.br/noticias/suplementos,sempre-alerta,285836,0.htm>. Acesso em: 21 set. 2011.

O CONAR cria normas éticas para apelos de sustentabilidade na publicidade. Disponível em: <http://www.conar.org.br/html/noticias/070611.html>. Acesso em: 27 fev. 2012. OLIVEIRA, M.; GOMES, L. A praga das consultas a jato. Isto é, São Paulo, ano 35, n.2196, 15 dez. 2011. Disponível em: <http://www.istoe.com.br/reportagens/182300_A+PRAGA+DAS+CONSULTAS+A+JATO. Acesso em: 28 fev. 2012.

O ESTADO de São Paulo. Após crise, divida alta e nova bolha de ativos assombram paises. 18 nov. 2009. Disponível em: <http://www.estadao.com.br/noticias/economia,apos-crisedivida-alta-e-nova-bolha-de-ativos-assombram-paises,468401,0.htm $>$. Acesso em: 23 nov. 2009.

O QUE É ENEF. Vida \& dinheiro: educação financeira. Disponível em:

<http://www.vidaedinheiro.gov.br/Enef/Default.aspx>. Acesso em: 03 maio 2012.

OSCAR, N. Zara é envolvida em denúncia de trabalho escravo. O Estado de São Paulo, São Paulo, 17 ago. 2011. Economia \& Negócios. Disponível em:

$<$ http:/ / economia.estadao.com.br/noticias/neg\%C3\%B3cios,zara-e-envolvida-emdenuncia-de-trabalho-escravo,80618,0.htm>. Acesso em: 27 fev. 2012.

PESQUISA CNC. Endividamento e inadimplência do consumidor. CNC: Confederação Nacional do Comércio de Bens, Serviços e Turismo, fev. 2012. Disponível em: <http://www.cnc.org.br/sites/default/files/arquivos/release_peic_fevereiro_2012.pdf >. Acesso em: 02 mar. 2012.

PESQUISA de juros. ANEFAC: Associação Nacional dos Executivos de Finanças, Administração e Contabilidade, jan. 2012. Disponível em:

$<$ http://www.anefac.com.br/pesquisajuros/2012/pesquisa_de_juros_janeiro.pdf $>$. Acesso em: 02 mar. 2012.

PORTO, G. IBGE aponta PIB per capita estagnado em 2012. O Estado de São Paulo, São Paulo, 04 mar. 2013. Disponível em: <http://economia.estadao.com.br/noticias/economia-geral,ibge-aponta-pib-per-capita-estagnado-em-2012,145946,0.htm>. Acesso em: 06 set. 2013.

QUAINO, L. Alimentos têm alta influenciada pelo dólar e puxam inflação de agosto. G1 Economia, 06 set. 2013. Disponível em: <http://g1.globo.com/economia/noticia/2013/09/alimentos-tem-alta-influenciada-pelo-dolar-e-puxam-inflacao-deagosto.html>. Acesso em: 10 out. 2013.

RIO GRANDE DO SUL (Estado). Poder Judiciário. Corregedoria-Geral da Justiça. Os 10 mandamentos da prevenção ao superendividamento: cartilha do superendividado. Disponível em: <http://tj.pr.gov.br/web/je/10-mandamentos>. Acesso em: 08 set. 2011.

RODRIGUES, A. Oferta maior de crédito amplia PIB, diz BNDES. O Estado de São Paulo, São Paulo, 07 ago. 2010. Disponível em:

$<$ http://www.estadao.com.br/noticias/impresso,oferta-maior-de-credito-amplia-pibdiz-bndes,591593,0.htm>. Acesso em: 23 set. 2011.

SALEH, A. M.; SALEH, P. B. O. Consumo responsável: um passo além do aspecto 
ambiental. Educar em Revista, Curitiba, n.44, jun. 2012. Disponível em: <http://www.scielo.br/scielo.php?pid=S0104-40602012000200011\&script=sci_arttext $>$. Acesso em: 05 set. 2013

SALEH, A. M. A educação para o consumo responsável e a sustentabilidade: um casoexemplo. Educação Ambiental em Ação, ano IX, n.32, jun. 2010. Disponível em:

$<$ http:/ / www.revistaea.org/artigo.php?idartigo $=867 \&$ class $=02>$. Acesso em: 01 dez. 2010.

SALEH, A. M.; SALEH, P. B. O. Apresentação didática do projeto "Educação para o Consumo Responsável”. Revista Conexão UEPG, Ponta Grossa, v.1, n.6, p.28-33, 2010. Disponível em: < http://www.uepg.br/revistaconexao/revista/edicao06/4.pdf>. Acesso em: 01 dez. 2010.

SANDRONI, Paulo (Org.). Novíssimo dicionário de economia. São Paulo: Best Seller, 1999. SANTOS, J. J. Formação de preços: um enfoque prático adaptado à reforma econômica. São Paulo: Atlas, 1986.

SAVOIA, J. R. F.; SAITO, A. T.; SANTANA, F. A. Paradigmas da educação financeira no Brasil. Rev. Adm. Pública, Rio de Janeiro, v.41, n.6, dez. 2007. Disponível em:

<http://www.scielo.br/scielo.php?script=sci_arttext\&pid=S0034-76122007000600006 \&lng=pt\&nrm=iso $>$. Acesso em: 25 set. 2013.

SEGALLA, A.; VILLAMÉA, L. A geração do bem-estar. Isto é, São Paulo, ano 34, n.2128, p.42-47, 25 ago. 2010. Especial Nunca fomos tão felizes. Disponível em:

<http://www.istoe.com.br/reportagens/96874_A+GERACAO+DO+BEM+ESTAR

+PARTE+1>. Acesso em: 24 set. 2011.

TOSI, A. J. Matemática financeira com ênfase em produtos bancários. São Paulo: Atlas, 2003.

Recebido em: 28/05/2012

Aprovado em: 08/11/2013

Contato:

Departamento de Matemática e Estatística

Universidade Estadual de Ponta Grossa

Avenida General Carlos Cavalcanti, 4748

CEP 84030-000

Ponta Grossa | PR | Brasil 